\title{
3
}

\section{EMERGING ETHICAL ISSUES IN LIVING LABS}

Fausto J. Sainz (Technosite)

\begin{abstract}
Living labs represent an important step in the development of research solutions based on the inclusive design paradigm. To ensure participants' rights and the adoption of an ethical approach to technological research, this paper presents some tools and strategies that comply with the needs and rights of those less advantaged groups to ensure that their rights and demands are taken into account. There is a gap in the construction and development of norms for a living lab. This article summarizes the efforts made to achieve the goals of ethical awareness, enumerates the issues related to the ethical problems that may arise during participatory design and living labs environments, describes working routines, and outlines recommendations for achieving this objective. This paper attempts to focus on those aspects of research development that directly or indirectly come into contact with issues of ethics, privacy, and security related to participants in the context of any research conducted using a living lab approach. It also includes thoughts about the importance of information and communication technologies on the public domain and their implications for privacy. The importance of ethical awareness is even more evident in the case of enterprises where elderly and disabled users are present. For that reason, there are several legal tools that can be applied in a living lab setting, tools that are pertinent even though they may not have been conceived specifically to regulate this environment, may be used in a precarious way and might be temporary as well, just to proceed with the setting up of the living lab. However, the specificity and idiosyncrasy of this research environment demands further efforts to establish procedures that will facilitate both the proper set-up and smooth running of the living lab.
\end{abstract}


Keywords: Ethical issues, living labs, inclusive design, disabled, elderly, technology development, privacy, security, regulations.

\section{INTRODUCTION}

Living labs are new spaces of innovation where citizens provide the engine for validating and creating new ideas, developed as part of the userdriven trend in innovation. They are open innovation instruments already acknowledged in Europe, according to Mulder et al. (2008). Living labs started as a way of including participatory design in the rural environment. It is an approach to stimulate user-driven innovations in order to better understand and exploit these innovations. This approach encourages the potential that can be unleashed by putting the customer into the driver seat of innovations. In it, companies, public organisations, research centres and citizens are involved in the innovation process by co-creating and validating technologies, platforms, products, services and business models in real-life contexts. However, while more and more enterprises and regions in Europe and all over the world are starting to commit themselves to the basic principles and guidelines of the living lab approach, there is not enough information to cope with the ethical issues that are constantly arising in these innovative projects and enterprises. This paper presents concerns about ethical issues in the living lab environment. Specifically, it tries to solve the problem of the lack of ethical guidelines on building and developing any living lab. It is hoped that this development can guide both the course of action and the procedure in the case of unexpected related events that would require action.

Translating ethical principles into ethical practice is a minefield (Swain et al., 1998). In this sense, trying to develop a set of ethical guidelines might not fit every project's needs. However, it is hoped that by doing so at least less harm can be done by the developer's ignorance. These guidelines can serve the purpose of ensuring the developers' awareness of their ethical responsibility as proposed by Gram-Hansen (2009).

Although there are important similarities between living lab practices and laboratory settings -which are sometimes even part of living labs- there are also differences to consider and other ethical issues to deal with. For a start, it is difficult to talk about intentional research in a living lab environment, 
thus avoiding the need for guidelines on these aspects (Baumrind, 1985). Laboratory settings offer the advantage of providing technical equipment that can record and support the experiments while also facilitating stable conditions, thus making the experiments and tests comparable (Dix et al., 2003), and their approach to volunteer participation is clearly regulated by European and national norms. On the other hand, the innovative living lab approach would benefit from guidelines and regulations on the ethical aspects inherent to its voluntary and participatory nature. The environment has what Turilli has called the ethical consistency problem (2007), in which it is difficult to constrain different actors to ensure that the overall output is ethically consistent. The living lab environment is certainly an area where constant innovation has been produced and new hypothetical human-computer interactions and ethical issues can be explored. Therefore, designers and stakeholders need to place themselves at the boundary between current experience and future expectations while considering the implications for the relationships that might develop. Understanding new technologies and their possible uses as well as the reciprocity between technologies and humans is essential to harness any future design. There is also another factor to take into account: the importance of the different knowledge, experience and expertise that can be brought into play as needed.

In the field of innovation, especially where testing and piloting are carried out using existing technologies and adapting new ICT trends, it is important to take into consideration the legal and ethical requirements regarding users' interactions and technological developments. It is very important to establish ethical guidelines endorsed by society so that ICT developments behave accordingly (Turilli, 2007).

The inclusion of information and communication technology in public places, social spaces, homes and everyday life in general arouses a number of ethical dilemmas concerning security, privacy (Sixsmith and Müller, 2008), freedom of choice, dependency and consent which must be very carefully considered. How we receive and process the information around us largely determines the extent to which we are able to participate in the world in which we live. These considerations are, if anything, paramount in the case at hand when dealing with people with functional diversity who are more vulnerable to possible wrongdoing, either intentional or not, in the area of applied research. Special care should be taken in those systems and devices that are being developed or evaluated within the framework of technological research when they affect people who 
are not fully able to understand, control or manipulate the technology themselves, such as those with cognitive or mental disabilities. Therefore, it is necessary to have a frame of reference and legal information on the research and validation process to cover these issues and to guide rather than solve any problems that may arise during the course of the research. The development of applied ethics has been implemented since the mid20 th century in several fields, and recently ethicists' focus is moving from consequences to the design and shaping of technology (Albrechtslund, 2007). They are also considering aspects of information processing and those of a psychological and social nature.

\section{NORMS AND LEGISLATION SUPPORTING THE ELDERLY AND DISABLED}

Generally speaking, ethical awareness in relation to technology has been growing in European and international organisations for the past decade. Indeed, these ethics are embedded and legally binding in the Sixth and Seventh Framework Programmes and thus characterise research and development in the European Union and beyond.

Respect for fundamental rights is a key element in understanding the promotion of research and industrial applications in Europe that are consistent with European values. The Treaty of Lisbon, the Charter of Fundamentals Rights of the European Union and the Commission's Green Paper on the European Research Area all identify a set of European values that frame the implementation of EU policies, including all policies related to research and technology. In the area of research, the goal of these norms is to ensure that European ethical principles are respected and rooted in these activities.

Therefore, in the case of living labs as research entities, there is a need for legal and normative frameworks and guidelines to be included from the beginning of the project, even at its conception. As stated by Magnusson et al. (2003), ethical issues arose "immediately prior, during and shortly after the field study periods". For this reason, it is important to plan in advance and be prepared to solve those issues. Research processes are inherently laden with ethical dilemmas that cannot be predicted at the beginning (Swain et al., 1998), and although they pervade the entire process and dilemmas need to be addressed and negotiated, they are dealt with in the particular context of the research and nonetheless benefit from 
guidelines. Advances in ICTs raise new ethical issues, and human values must be integrated into ICT developments so they are protected rather than damaged by these advances. We have seen (Kanis et al., 2009) how technology has the potential to improve people's quality of life. There are certain effects that living labs have on a social and political level, in addition to their personal effects, setting aside possible technological advances. As heterogeneous collaborative work environments, living labs seem to have the power to raise ethical issues that affect humans simply through their human interaction capabilities. One indicator of the importance of allowing elderly and disabled users to actively participate in any research project is the consideration of users as partners in the research and development phases of any project because they are both "a market force and valuable source of input, as Buhler (2001) stated almost a decade ago.

Alongside conceptual evolution, one of the current challenges is to develop systems and tools that help to implement these integrated policies. After that, we will have to develop assessment tools that allow for ethical assessment; implementation of these policies and help the acquisition of these procedures in different realities, and specifically for these new research and development environments such as living labs.

\section{ETHICAL ISSUES RELATED TO LIVING LABS}

The living lab project should be aware of the need to develop research in its ethical dimension not only from the perspective of legality but also to take into account the ethical considerations of the group with which you work. Any research project developed in a living lab environment dealing with autonomy and independent living raises several moral and ethical issues dealing with personal freedom, autonomy, privacy and responsibility.

Although ethical concerns are somehow indirectly reflected in the code of conduct of the professional organisations to which some of the researchers belong, it is still necessary to include them in most strategic plans during the early phase in the creation of living labs. These professional codes can provide guidance and contain different rules that deal with most issues a professional is likely to face, but the uncertainty and the varied orientation of living labs requires a clearly established process and clearly articulated decision-making procedure to deal with such instances. Therefore, it seems reasonable to develop a set of guidelines that provide 
information to help members to deal not just with situations reflected in the codes but also with any situations that arise during the research period.

There is a need to protect the more vulnerable participants, including the elderly and individuals with cognitive disabilities, bearing in mind that some research projects are aimed specifically at those target groups. On the other hand, there is a clear demand for accessible products and services and an opportunity to create innovative new accessible mainstream products. In this sense, the ethical issues concerning the research and development of living labs can be categorised into two strands: the ethics of the process and the ethics of the product, similar to what was set forth by Ikonen et al. (2000).

During the development of a living lab, conflicts of interest are likely to arise among all the participants, stakeholders, moderators, etc. These conflicts occur not only between volunteers and moderators but often between different parts of the consortium member organisations. The successful development and implementation of new systems is therefore a process of negotiation between the affected and interested parties. Obviously, the most important affected and interested parties include the users themselves, and if they are left out of the decision-making process the process of change is unlikely to be successful. It is essential they participate in the design and development process as they have so much to contribute towards making the implementation a success.

In addition to this, there are unavoidable conflicts emerging from the different roles involved in the project. These conflicts are not simply between researchers and participants but often between research managers and researchers, and participants and managers, or other combinations. The successful development of the research process is therefore a negotiation process between the affected and interested parties. It is recognised in practice that participation in living labs or any other form of "disinterested" product development means different things to different people and that the parties involved may have different reasons for wanting to participate and quite different expectations concerning the benefits of such participation.

Another factor that can affect the decision-making process is related to the awareness participants in the living lab have of the implications (including ethical implications) of a specific design. As demonstrated by Manders-Huits (2010), any design has ethical implications, and knowing that technology is value-laden, it is desirable to have means for ethically evaluating and justifying the decisions taken during technology design. Therefore, the participants in a living lab must be aware of these circumstances that surround the 
design and/or co-design activities. Co-design activities are a very popular collaborative tool in living labs. An additional problem of this cooperative dynamic is the uncertainty of whether all stakeholders are reached. Even when it is ascertained that all direct and indirect prospective users are included in the process and the technology assessment is underway, there is the honesty issue which derives from several factors: What if certain stakeholders push their views in the evaluation session (or process), even when their views are opposite to those of the main beneficiaries of the technology? What about peer pressure during these sessions? During this design process, it is also very important to distinguish between stakeholders' moral values and mere preferences, wishes and whims, and between what they consider to be important and what truly is important. To solve this problem, a list of values can be drawn up, but then the problem is that the list with its different priorities can be arbitrary. Thus, it seems necessary to establish criteria that will satisfy everyone involved, and these criteria have to be a combination of moral universality and moral variability. A middle ground such as the one proposed by Friedman $\sigma^{\circ}$ Kahn (2003), in which a design needs to be robust enough to support the value being considered while also adaptable enough for different cultures to use it in their own way, seems to be an appropriate solution.

Pressure to participate can be another ethical issue that might arise as the project unfolds, and not just in the beginning stages. Even when participation is voluntary and information about the project is presented clearly, it might be difficult not to join due to group pressure (Löfman et al., 2004). As mentioned above (Magnusson $\mathscr{G}^{\circ}$ Hanson, 2003), the right to withdraw from the project or refusal to participate in certain activities can become more difficult for participants to exercise. However, there is usually a reciprocal relationship that respects the ethical principle of respect for individuals when the team members support the participants and the researchers value the information and insight provided by the participants. This situation especially applies to the most vulnerable groups: cognitively disabled participants and the elderly.

In the case of the cognitively disabled, the disappointment issue can also be examined from another point of view: the development of emotional ties or bonds with members of the project, both members of the research team and fellow participants. This can also happen to the population at large, but in the case of the cognitively disabled involvement can seem to be not just peripheral or anecdotic (Swain et al., 1998), and emotional attachment can occur. 
PRIVACY AND SECURITY

There are different behaviour patterns associated with different social relationships, and we establish those patterns according to their appropriateness; therefore, certain behaviour patterns are expected from a professional in a working environment, while a different pattern is expected from that same person in a family setting. In the living lab environment, it is essential to distinguish among the different roles that people can play depending on the situation (Rachels, 1975). Sometimes privacy is inadvertently invaded, and both the researchers and volunteers might feel that some information about them pertains to a specific relationship, a relationship that entitles the other side to inquire about such facts. If we cannot control who has access to us and who we can include or exclude in our relations, we may not be able to regulate our behaviour properly. This important issue, which is particularly relevant in a collaborative environment such as the living lab, is followed by another position (Swain et al., 1998) in which as long as users or participants can exercise control over the processes of data collection and reporting there is a sense of respect.

There is a rise in the use of technologies that are ubiquitous and invisible, technologies that do not require much knowledge on the part of the user. Such technologies, embedded in the environment, do not allow users to choose their interaction (Mordini et al., 2009). These technological changes will affect how people interact with ICTs and how the perceptions of these technologies are developed. Participants in living labs must be aware of the importance of evaluating these devices and their consequences. It is necessary to understand the relationship between privacy and research in this inclusive research environment in the same way as the relationship between privacy and smart home information technologies (Courtney, 2008), especially when the participant or resident cannot choose whether or not to adopt them.

PSYCHOLOGICAL AND SOCIAL CONSIDERATIONS

Active participation in a research project framed in a living lab environment may arouse feelings, stir memories or revive participants' negative or extreme feelings and emotions that otherwise would have been left undisturbed. The effects of this negative emotion can have on participants must be considered. This issue, which must be taken into 
account when co-designing in the living lab environment, is joined by the possibility of unwanted disclosures which could arise when working with the cognitively disabled. As stated by Swain et al. (1998), in cases in which disclosures or unwanted information that might be regretted later appear during the research process, informed consent becomes not just a formality at the outset of research but a continuous process that has to be constantly reaffirmed.

As living labs are particular spaces with their peculiar cultural milieu, the values added to it emanating from the people in the group might be too local and not completely ethically correct for the rest of society. Another consideration is that due to the acquisition of new information, insights and experiences people's opinions vary, including their beliefs (Manders-Huits, 2010) and thus the ethical considerations.

Conflict may arise when a proposed product or service developed, which is considered to be extremely important or even critical for the living lab founders, is rejected by the users. Another kind of conflict may erupt when a partner that is funding the research environment forcibly suggests the use of one of its products, even though that product is not welcomed by users. If one of the stakeholders tries to use coercive force to satisfy its needs and wishes, the result is an imbalance in the decisionmaking process that has the effect of invalidating, if not the whole results from that particular activity, at least the ethical soundness of that forceful partner belonging to the industry environment.

When there are participants that are resistant to change for any reason, the other participants in a living lab can encourage them to change their understanding and use of technology. However, we must ask ourselves about both the effects and the effectiveness of this action. If colleagues are successful in their illustrative tasks, then it will interfere with the participants' original will, thus triggering the loss of an original yet different perspective.

\section{FORCIBLEACCEPTANCE OF TECHNOLOGY}

Some people are coming to reject the pressures of the normalising society that obliges citizens to adopt technology and consumer products into our everyday lives. They are learning to despise the whole range of market, family and organisational pressures which attempt to reinforce this consumerism and these technophile attitudes. Following this line of 
thinking, we can conclude that society is what has to bow to and accept the fact that certain groups of citizens do not want to technological aids and should not be forced either directly or indirectly to pursue the technological competence required to use these newly-developed products.

There are also differences between elderly people and disabled users of technology. Why is it always assumed that new technologies are a step forward? The issue of technology acceptance opens the floodgates to the fact that not everybody embraces technological developments enthusiastically, and that in turn leads to the fact that not only practitioners, researchers and designers might be interested in finding out why people may resist using new technology.

\section{OTHER ISSUES}

To preserve the dignity, autonomy and values of the end users and project participants, this project addresses the ethical perspective from the very beginning. Managing the ethical issues within the project is the responsibility of the different entities involved in the project management structure. A body responsible for decision-making in event of ethical issues that need to be resolved by a decision-making process should be set up within the research consortium.

Ethical dilemmas can occur in many ways, often when we least expect them. The ideal way to avoid having to make a difficult decision is to minimise the chances of having to make one in the first place. A risk management approach to ethics provides a practical way to avoid ethical dilemmas, although it has some ethical (and personal) liabilities of its own. The key to effective risk management is to scrupulously uphold the tenets of the relevant laws, policies, professional standards and ethics codes, taking as many steps as possible to avoid ever being placed in precarious ethical or legal circumstances. Early recognition of the risks that involve ethical decisions and having a little lead time to think the matter through can prevent many potential ethical problems from escalating to the point of causing harm. Risk management strategies include examining good practices and referring to existing guidelines and documentation.

At the time that the collaborative environment, project plan and arrangement are presented, it is also important to take into account how the real or expected economic implications in the here and now could affect people's decision-making processes in the future. 


\section{RECRUITMENT CRITERIA}

The possible ethical implications of employing disabled workers must be taken into account, assuring accessibility from the development stage to the final operational period. Recruitment criteria should be undertaken addressing the principles of individual autonomy, respect for human dignity, non-discrimination, proportionality, non-exploitation and the protection of vulnerable individuals. The users' participation in this project should be on a voluntary basis.

The following areas need to be explored and studied in order to develop both tools and strategies to cope with the questions that will surely arise as the project advances:

- The policy, rules and regulations applicable.

- Personal data privacy, security and safety.

- Treatment of disappointment: It is necessary to clearly establish the purpose or objectives of the tool to be developed so there is no sense of disappointment.

- Content reliability. The reliability of the content provided must be assured.

- The service should act like and offer the services expected of a tool of its kind.

- The service provided should endorse modern society's ethical principles, especially those related to equality and the rights of individuals with disabilities.

- Intellectual property issues.

It should not be forgotten that for participants, their involvement in tests activities can be quite a distressing experience because they may feel tremendous pressure to perform. This happens even when they are informed that the purpose of the study is to test the system or the particular software and not them as users.

Likewise, certain participatory design methodologies that involve collaboration with prospective users have been criticised as masking subtle exploitation (Hart $\sigma^{\circ}$ Bond, 1995).

What happens when one form of interaction is more effective than one previously adopted (Beaudouin-Lafon, 2004) yet only a handful of applications use them? If studies offer a solution that is not accepted by the participants, what should the researcher do? It is important to design 
for interaction rather than designing for interfaces in the case of humancomputer interaction.

Users are morally entitled to have a say in the tools they are going to use, as they might change everything (Carroll $\sigma^{\circ}$ Rosson, 2007). Yet at the same time, the formation of participants' moral character is dependent on repeated engagement in activities, including obviously those activities developed in the living lab environment. As noted by Vallor (2010), those actions will eventually promote the development of virtues or perhaps vices, and therefore it is important to consider the extent to which a given technology could impact the moral development of the people participating. In the living lab environment, the effect of social contact could also be included.

What responsibilities do participants have in the co-design experience (for both good and bad results)? Just as with other participatory techniques, knowledge is an important issue in terms of both intellectual property rights and the terms in which the participants are considered. Even when participation elicitation techniques are supposed to facilitate personal input from all the volunteers on equal terms, there is no guarantee that all participants' individual inputs will be considered on an equal basis. Even though as participants they give their time and trust, and this has to be respected (Puri et al., 2004), it is very important to discuss and explicitly outline participants' different roles (Jansson et al., 2008) at the beginning of the project, it if is deemed necessary.

Along with this issue is the issue of intellectual property. Intellectual property rights can be directly affected in a living lab situation, especially if this issue has not been clarified from the beginning. It is necessary to state whether intellectual property is shared among all the stakeholders, and this is a delicate matter since it is very difficult to quantify the participation and knowledge provided by each participant and thus identify the implications in terms of research ownership. As stated by Jansson (1975), a great deal of knowledge is possessed and produced collectively, even more so in a living lab environment.

\section{GOOD PRACTICES}

The recommendations presented in this article are to be understood as a continuation of the professional codes of conduct of professional bodies that already exist. It seems necessary to provide this information flow, which encourages these organisms to update their standards and is 
relevant for research professionals, as stated by Prior et al. (2010). Even though most uncertainties would be addressed correctly following the legislation and existing norms, we can nonetheless provide some actions that might prevent wrong practices from arising.

User empowerment must be done carefully so the knowledge acquired by experts over the years is not ignored by misinformed users. The balance between the technical knowledge provided by technicians and the drive from citizens is not easy to achieve unless both sides are well aware of both their limitations and their capabilities. Thus, both formal and informal meetings would help to each side to understand each other's role in the process as well as the fact that stakeholders' expectations, knowledge and views are different. However, the ultimate objective is the same: the production of goods or services that improve people's quality of life both in the community and as individual entities.

If there are ethical implications that arise during the process, they should be made understandable and manageable to both users and developers.

In order to achieve this goal, two approaches can be used depending on the specific situation:

1. Strategies: With these strategies it would be possible to avoid having to take ethical decisions and, in the case of unavoidable situations where a decision has to be taken, strategies are an efficient means to address any ethical issue that might arise during the project.

2. Tools: The development and gathering of efficient tools that serve to monitor, guide and control situations in which ethical issues have to be dealt with and solutions need to be offered. With regard to these tools, it is imperative to be aware of the legal requirements, rules and regulations in force.

On the other hand, the consortium has to be coherent in its ethical standpoint, so accessibility has to be included in all the project areas: from the recruitment of disabled individuals to the assurance of accessibility to the working tools and media and products that are developed or used during the work, including the recruitment strategies and policies.

To achieve a holistic approach to ethical issues related to the work in living labs, the selection of different tools and techniques used during in the living lab should be guided by the time of the project development, the stage of the project, the resources available, the research objectives and other considerations. Everything should be checked and compared via a monitoring procedure to ensure that the objectives are met and that they follow ethical principles. 


\section{CONCLUSIONS}

It seems hard to reconcile professional responsibility, which is committed to obtaining user satisfaction, with scientific responsibility, which aims for research conducted properly to achieve results that, in turn, support future users. At times, these results are obtained without taking users' wishes or preferences into consideration.

Although it is necessary to make values explicit in case of ethical evaluation in innovation, as proposed by Mordini et al. (2009), it is difficult to define the specific criteria for evaluating the vulnerability of everyone participating in the living lab environment, where elderly and cognitively disabled groups are especially at risk. Perhaps the guidelines proposed herein might help to set ethically sound practices in the living lab environment and comply with the Riga Declaration on ethical awareness in ICTs while more elaborate procedures are being developed.

Tentative suggestions have been put forward as to how some of the identified problems might be tackled. On the other hand, issues related to closer relationships among the research stakeholders in living labs, such as mentors and other supporting figures, have not been examined in depth. In the case of mentoring, the issues that can affect mentees are not related solely to the work environment but also encompass a broader sphere, including their personal lives.

Acknowledgments. We would like to thank the Spanish Ministry of Industry, Tourism and Commerce, the PNICDT 2008-2011 programme and the European Regional Development Fund (ERDF) for grant TSI020301-2008-21 which co-funded the CISVI project.

\section{BIBLIOGRAPHY}

Albrechtslund, A. (2007), "Ethics and technology design". Ethics and Information Technology 9, 63-72.

Baumrind, D. (1985), "Research using intentional deception. Ethical issues revisited”. American Psychologist 40 (2), 165-174.

Beaudouin-Lafon, M. (2004), "Designing interaction, not interfaces. In Proceedings of the Working Conference on Advanced Visual Interfaces" (Gallipoli, Italy, May 25 - 28, 2004). AVI '04. ACM, New York, NY, 15-22. Carroll, J. M. and Rosson, M. B. (2007) Participatory design in community informatics. Design Studies 28 (3), 243-261. 
Buhler, C. (2001), "Empowered participation of users with disabilities in REDD projects". International Journal of Human-Computer Studies, 55 (4), 645-659.

Cordis (2007), Additional Information on Ethics related to undertaking ICT research in FP7. http://cordis.europa.eu/fp7/ethics-ict_en.html Courtney, K. L. (2008), "Privacy and senior willingness to adopt smart home information technology in residential care facilities". Methods Inf Med. 47(1), 76-81.

Dix, A., Finlay, J., Abowd, G. $\sigma^{\circ}$ Beale, R. (2003), Human Computer Interaction. Prentice Hall.

ETSI TR 102415 V1.1.1 (2005-2008) Human Factors (HF); Telecare Services; Issues and recommendations for user aspects. European Telecommunications Standards Institute 2005.

Friedman, B. $6 \sigma^{\circ} \mathrm{Kahn}$, P. H. (2003), "Human values, ethics and design". In J. A. Jacko $\sigma^{\circ}$ A. Sears (Eds.), The Human-Computer Interaction Handbook, 1177-1201. Lawrence Erlbaum Associates, Mahwah.

Gram-Hansen, S. B. (2009), "Towards an approach to ethics and HCI development based on Løgstrup's ideas”. In T. Gross et al. (Eds.), Interact 2009, Part I, Springer Verlag, LNCS 5726, 200-203.

Hart, E. Eפ Bond, M. (1995), Action Research for Health and Social Care: A Guide to Practice. Open University Press, Buckingham, UK. Ikonen, V., Väyrynen, S. $6^{\circ}$ Tornberg, V. (2000), "New technology in health and social services - ethics and ergonomics in videotelephone use among workers and clients". In Fostervold K.I. E于 Endestad T. (Eds.) (2000), Proceedings Fra Nordiska Ergonomisälskapets Arkonranse. Nordiska Ergonomisälskapet (NES) i samarbeid med Norsk Ergonomiforeninig (NEF), Oslo, 27-30.

Jansson, M., Mörtberg, C. छ9 Mirijamdotter, A. (2008), "Participation in e-Home Healthcare @ North Calotte". In Proceedings of Nordichi (2008), Using Bridges, 12-22 October, Lund, Sweden. 192-200.

Kanis, M., Brinkman, W-P. Eீ Perry, M. (2009). "Designing for positive disclosure: what do you like today?". International Journal of Industrial Ergonomics 39, 564-572.

Löfman, P., Pelkonen, M. Eจ Pietilä, A-M. (2004), "Ethical issues in participatory action research". Scand J Caring Science 18, 333-340.

Magnusson, L. $\sigma^{\circ}$ Hanson, E. (2003), "Ethical issues arising from a research, technology and development project to support frail older people and their family carers at home". Health and Social Care in the Community 11 (5), 431-439. 
Manders-Huits, N. (2010), "What values in design? The challenge of incorporating moral values into design". Science and Engineering Ethics, 17, 271-328.

Mordini, E. et al. (2009), "Senior citizens and the ethics of e-inclusion". Ethics and Information Technology 11, 203-220.

Müller, S. $\sigma^{\circ}$ Sixsmith, A. (2008), "User requirements for ambient assisted living: results of the SOPRANO project". Gerontechnology 7 (2), 168. Mulder, I, Velthausz, D. 60 Krien, M. (2008), "eJOV Executive". The Electronic Journal for Virtual Organizations and Networks 10. Special Issue on Living Labs.

Prior, M., Fairweather, N. B., Rogerson, S. Eं West., D. (2010), Is IT Ethical 2010: Survey of Professional Practice. Institute for the Management of Information Systems. Kent

Puri, S. K., Byrne, E., Nhampossa, J. L. $\sigma^{\circ}$ Quraishi, Z. B. (2004), "Contextuality of participation in IS design: A developing country perspective". In Proceedings of the Eighth Conference on Participatory Design. ACM Press, New York, 42-52.

Rachels, J. (1975), "Why privacy is important". Philosophy and Public Affairs, 4 (4), 323-333.

Rogerson, S. (2007), "E-inclusion Ethics". ETHIcol IMIS Journal 17 (7). Turilli, M. (2007), "Ethical protocol design". Ethics and Information Technology 9, 49-62.

Swain, J., Heyman, B. $\sigma^{\circ}$ Gillman, M. (1998), "Public Research, Private Concerns: Ethical issues in the use of open-ended interviews with people who have learning difficulties", Disability and Society 13 (1), 21-36.

Vallor, S. (2010), "Social networking technology and the virtues". Ethics in Information Technology 12, 157-170.

Fausto J. Sainz

Technosite

fsainz@technosite.es

This paper was received on December 20, 2011 and was approved on January 20, 2012 